\title{
Effects of laser-assisted cosmetic smile lift gingivectomy on postoperative bleeding and pain in fixed orthodontic patients: a controlled clinical trial
}

\author{
Farhad Sobouti ${ }^{1}$, Vahid Rakhshan ${ }^{2,3}$, Nasim Chiniforush ${ }^{4}$ and Maziar Khatami $5^{*}$
}

\begin{abstract}
Background and objective: Diode lasers are becoming popular in gingival treatment following orthodontic treatments. Despite their merit and clinical implications, postoperative pain and bleeding after surgery with diode lasers are not assessed except in few controversial studies.

Method: This controlled clinical trial was conducted on 30 healthy orthodontic patients aged 17-29 years, needing esthetic-only gingivectomy in the anterior maxilla. The patients were randomly divided into two groups of 15 each: experimental (laser-assisted surgery) and control (traditional surgery using scalpels). The bleeding rate following the surgery was assessed using the bleeding criteria established by the World Health Organization. The postsurgical pain level was recorded using visual analog scales immediately after the surgery and in patients who consumed analgesics, also $2 \mathrm{~h}$ after the analgesic consumption. The data were analyzed using the independent-samples t, Mann-Whitney $\mathrm{U}$, and chi-square tests $(a=0.05)$.

Results: The average bleeding rates were 1.15 and 0.36 in the conventional and laser groups, respectively (Mann-Whitney $\cup P<0.05)$. Experimental patients had no postsurgical pain $(V A S 1$ and VAS2 $=0$ ). In the control group, the average VAS1 pain was 5.2 out of 10 . The difference between VAS1 values in the control/experimental groups was significant (Mann-Whitney $\cup P<0.001$ ).
\end{abstract}

Conclusion: 940-nm diode laser seems promising in reducing postoperative bleeding and pain of patients needing cosmetic smile lift surgeries.

Keywords: Cosmetic smile lift; Gingivectomy; Diode laser; Orthodontics; Periodontics

\section{Background}

With an ever-increasing number of adults seeking orthodontic treatment, the improvement of patients' esthetics has become one of the main goals of orthodontics [1-5]. The gingival esthetics plays a major role in this regard [6]. Disproportionate dentogingival relationships might negatively affect the outcome of treatment, even if the teeth are perfectly aligned $[7,8]$.

Orthodontic treatment might affect gingival health [9-11]. In certain cases, the gingival margin needs recontouring by

\footnotetext{
* Correspondence: mzkhatami@gmail.com

${ }^{5}$ Department Of Periodontics, Dental Faculty, Mazandaran University of Medical Sciences, Sari, Iran

Full list of author information is available at the end of the article
}

means of gingivectomy [12]. However, the costs and postsurgical pain of this treatment might discourage patients, unless in severe cases $[7,13]$. Pain is one of the most important and common postoperative complications, which can discourage patients from seeking treatment; and its proper control might leave a good impression on the patient regarding the quality of surgery [14-20].

Lasers have been useful in various fields, including orthodontics [21]. With the introduction of soft tissue diode lasers, which might be economic and less painful than conventional methods, the gingivectomy treatment became a routine part of orthodontic treatment. Diode lasers might provide proper hemostasis, reduce the infection risk, and prevent damage to the teeth and bone because of 
their effect range which is limited to soft tissue [7]. They also might improve esthetics while improving soft tissue healing [3,6,22]. Edema, less swelling, and faster healing are the advantages of laser usage in soft tissue management $[23,24]$.

Gingivectomy can be performed by different means such as scalpels, electrosurgery, chemosurgery, and laser [25]. The conventional surgery performed by a small scalpel has been considered the most common method [25-27]. However, the advent of diode lasers highly absorbable by melanin and hemoglobin allows soft-tissue manipulations such as gingival recontouring, operculectomy, or frenectomy accompanied by improved epithelization and wound healing $[22,28,29]$. Lasers can incise the soft tissue to a depth of 2 to $6 \mathrm{~mm}$ [25]. The localized heat causes coagulation, protein denaturization, drying, vaporization, and carbonization at the site of the energy absorption. This might seal blood vessels and inhibit pain receptors at the incision location $[27,28]$. Therefore, using diode lasers might be advantageous because of better control, potentially lower pain and inflammation, and improved wound healing [22,27,30,31]. Despite these potential advantages, there is only one study comparing traditional method of surgery versus diode laser-assisted surgery in orthodontic setups, which did not enroll a uniform sample of surgeries [27].

In view of the lack of any studies comparing diode laser with scalpel in gingivectomies, this study was conducted. Its objective was to evaluate comparatively the effects of 940-nm diode laser on postoperative bleeding and pain, in orthodontic patients needing cosmetic smile lift gingivectomy. The null hypotheses were that surgery using diode laser versus scalpel would result in a similar level of postoperative bleeding and pain.

\section{Methods}

This controlled clinical trial was conducted on 30 patients undergoing fixed orthodontic treatment during 2012 to 2014. The sample size was predetermined as similar to the previous studies' sample sizes $[25,27,32]$. The protocol ethics were approved by the ethics committee of Mazandaran University of Medical Sciences. All patients were aware of their presence in this study, signed the consent form, and could leave at any time. Patients were selected about 1 month before the completion of their orthodontic treatment. The candidate patients were instructed to maintain a proper level of oral hygiene in order to keep their gingivae healthy.

The exclusion criteria comprised non-orthodontic patients, orthodontic patients with poor oral hygiene, orthodontic patients needing ortho-surgical treatment for esthetic purposes, patients having trismus and limited mouth opening, or those with a history of systemic diseases or any kind of disorders that could affect bleeding as well as pain perception directly or through the taken medications.
The inclusion criteria were patients with no/minimum gingival inflammation/pathology but needing esthetic-only gingivectomy (cosmetic smile lift) in bilateral upper incisors and canines after orthodontic treatment. The included patients needed to be skeletally normal and not needing esthetic skeletal surgeries or any underlying bone removals. Their need for esthetic post-treatment gingivectomy would be determined by an orthodontist and a periodontist, based on micro-esthetic criteria for assessing the alveolar bone height.

\section{Surgery}

The orthodontic treatments were performed by an orthodontist at a private clinic in the Sari city. After finishing the treatment, patients who had minimum gingival inflammation were again asked and taught to improve their oral hygiene and plaque control. Two weeks later, they were assessed by the periodontist and orthodontist. They were enrolled in the study if they had no/minimum gingival inflammation. The surgeries were carried out by a periodontist at a private dental center. The patients were randomly divided into two groups of control (15 subjects who received the conventional surgery using scalpels) and experimental (15 subjects who underwent laser gingivectomy). The randomization was done by the orthodontist and periodontist together, according to the order of the approved patients: the approved patients with odd numbers would be sequentially assigned to the conventional group and those with even numbers would be assigned to the laser group.

In the laser group, the local anesthesia was carried out by the topical application of TAC 20 gel (20\% lidocaine, 4\% articaine, $2 \%$ phenylephrine) to the area. Immediately after the beginning of the operation and also during the surgery, patients would be asked about their sensed pain and discomfort. If they sensed any pains, they would receive infiltration injection of 2\% lidocaine plus 1:100,000 epinephrine, upon their request until the surgery was performed under complete local anesthesia. In the laser group, no patient asked for extra anesthesia.

In the control (conventional surgery) group, topical TAC 20 gel was applied similar to the laser group. It did not suffice and the patients expressed pain. They received the infiltration injection of $2 \%$ lidocaine $(1: 100,000$ adrenaline). The surgeon asked the patient repeatedly regarding any perceived pain or discomfort, in order to make sure that the operation was carried out under absolute anesthetic conditions.

The extent of soft tissue removal in each patient was determined by the periodontist and the orthodontist together. The surgeon used a scalpel (carbon, No. 15 C) in the control group to trim and form the gingival margin. In the laser group, patients were treated for $30 \mathrm{~s}$ per tooth by a $940-\mathrm{nm}$ diode laser (diode Epic, BioLase, USA) with a 400- $\mu \mathrm{m}$ fiber at $0.9-\mathrm{W}$ power. During the gingivectomy, the laser tip was 
held vertically over the gingival margin. By means of a continuous laser beam, the gingival tissue was removed and formed. At the end of the surgery, about a 1-mm gingival sulcus depth remained $[23,26]$.

After achieving the ideal gingival contour and a proper height of the clinical crown, the surgery region was cleansed with a cotton roll or microbrush soaked in 3\% hydrogen peroxide. When needed (determined by the periodontist), the area was sutured with 3-0 stitches.

\section{Bleeding assessment}

Postsurgical bleeding was determined in both groups according to the WHO bleeding criteria: (grade 0) no bleeding, (grade 1) bleeding under the skin and petechial class, (grade 2) mild bleeding, (grade 3) gross bleeding, and (grade 4) mortal bleeding or annoying bleeding [33].

\section{Pain assessment}

The pain felt by the patients was evaluated using a visual analog scale (VAS) which was later converted to 11 ranked scores (0: no pain, 10: intolerable pain) as the initial VAS (VAS1) $[20,34]$. The included patients would be provided analgesics upon their request (Gelophen $400 \mathrm{mg}$, as many doses as wanted). The time to start taking analgesic was recorded for patients. About $2 \mathrm{~h}$ after taking the analgesic capsule(s), pain levels were investigated by a second VAS (VAS2), which was similarly converted to 11 ranks.

As an additional finding, the difference between VAS1 and VAS2 was calculated as an index of analgesic drug effect [27].

Statistical analyses were performed using the independent-samples $t$-test, chi-square and Mann-Whitney U tests of SPSS 20.0 (IBM, USA). The level of significance was predetermined as 0.05 .

\section{Results}

More than 300 fixed orthodontic patients who were supposed to be bracket-debonded in a month were evaluated during a 21-month period in 2012 to 2014 until the predetermined number of patients with no or minimum gingival inflammation but needing esthetic-only gingivectomy were enrolled. The excluded patients mostly needed additional or other treatments. Of the evaluated patients, 40 had had healthy gingivae needing esthetic issues in the anterior maxilla. Of these, 4 needed skeletal or bone manipulations and thus were excluded. Six were dropped out later (and replaced by new patients) because of their unacceptable gingival health at the surgery session (determined by the periodontist). The included patients aged 17 to 29 years old. Of them, 12 were males and 18 were females (Table 1). The average ages of the patients in the laser/experimental groups were not significantly different, according to the $t$-test $(P=0.974)$.
Table 1 Baseline age (year) and gender of the sample

\begin{tabular}{|c|c|c|c|c|c|c|}
\hline \multirow{2}{*}{$\begin{array}{l}\text { Group } \\
\text { Sex }\end{array}$} & \multicolumn{2}{|c|}{ Laser } & \multicolumn{2}{|c|}{ Control } & \multicolumn{2}{|c|}{ Total } \\
\hline & Male & Female & Male & Female & Male & Female \\
\hline Number & 5 & 10 & 7 & 8 & 12 & 18 \\
\hline Mean age (year) & 20.3 & 21.9 & 21.3 & 21.3 & 20.9 & 21.6 \\
\hline Standard deviation & 3.4 & 3.3 & 3.6 & 3.4 & 3.4 & 3.3 \\
\hline Minimum & 17 & 19 & 18 & 18 & 17 & 18 \\
\hline Maximum & 25 & 29 & 28 & 28 & 28 & 29 \\
\hline 95\% Cl upper limit & 16.0 & 19.5 & 17.9 & 18.5 & 18.7 & 20.0 \\
\hline 95\% Cl lower limit & 24.6 & 24.3 & 24.6 & 24.2 & 23.0 & 23.3 \\
\hline
\end{tabular}

$\mathrm{Cl}$, confidence interval.

The gender distribution was not significantly different between the two groups (chi-square $P=0.456$ ).

No harms were reported other than the pre-specified outcomes of pain-bleeding. None of the experimental patients needed suturing, scalpel incisions, or injecting local anesthesia. Nevertheless, 11 patients in the control group (73.3\%) needed suturing. The difference between the frequencies of suturing in both groups was statistically significant according to the chi-square test $(P<0.001)$.

\section{Bleeding}

The average bleeding rate in the control group was 1.15 (out of 4). This was significantly higher (Mann-Whitney U $P<0.05)$ than the bleeding rate observed in the experimental group ( 0.36 out of 4$)$.

\section{Infiltration injection of local anesthesia}

None of the patients in the laser group requested additional anesthetic doses. However, all the patients in the conventional group asked for extra local anesthesia. The difference between two groups in terms of their request for receiving analgesics was statistically significant (chisquare $P<0.001)$.

\section{Postoperative pain}

The experimental patients had no postsurgical pain $(\mathrm{VAS} 1=0)$. In the control group, the average pain was 5.2 out of 10. The VAS1 difference was significant (Mann-Whitney U $P<0.001$ ).

\section{Analgesic consumption}

Of the control and experimental subjects, 14 and none consumed analgesics, respectively. The 14 control subjects received the painkillers after an average of $82 \mathrm{~min}$. The frequency of analgesic consumption in the two groups was as well significantly different (chi-square $P<0.001$ ). About $2 \mathrm{~h}$ after taking the analgesics, the pain felt by the control subjects decreased to 1.2. 


\section{Discussion}

Previous studies have compared the laser with conventional surgery $[25,27,32]$. However, there are no studies comparing the 940-nm diode laser with the conventional surgery in gingivectomy patients, only. In the current study, the bleeding rate in the laser group was less than that in the control group. This was consistent with other studies on the decreased bleeding after laser-assisted surgery [25,27,32,33]. Laser can incise accurately, has a rather deep penetration, can induce coagulation, and is highly absorbed by hemoglobin. All of these factor might contribute to its appropriate hemostasis $[7,22,25,27,28,30-33]$.

Better coagulation also provides a dry and isolated environment, which allows a better control and less infection rate. This might be associated with reduced postsurgical pain $[20,35,36]$. The laser-assisted surgery had an astounding effect on pain among our patients. None of the patients treated with laser requested analgesics, while almost all control patients asked to receive painkillers. This was in agreement with other studies that reported a reduced pain level by using lasers $[25,27,32]$. This might be attributed to the less tissue trauma caused by the laser method [35,37]. The lower need for suturing in the laser group might as well imply this.

This clinical trial was limited by some factors. The subjective quality of pain influenced by interindividual and cultural/demographic variations affects its assessment $[20,34,38-44]$. Therefore, we used VAS, which is understandable by most patients, has proper sensitivity, and is reliable/reproducible [38-40,44,45]. As another limitation, analgesic consumption is a confounder of pain $[20,34,46,47]$. Therefore, we recorded the pain also before the analgesic consumption. Another limitation was the lack of blinding. However, the patients were not aware of the potential effects of laser on bleeding and pain. Thus, their responses were less likely biased by their knowledge of their group allocation. Moreover, it seemed impossible to blind the operator or the patient in such a design. The generalizability of this study might be reduced by the uniform sample of fixed orthodontic patients all needing esthetic-only gingivectomies, as this is not the case in everyday orthodontic practice. However, such a uniform sample was necessary to establish a proper level of internal reliability. Moreover, the results of this laser cannot be necessarily generalized to other types or wavelengths of lasers. Future multicenter trials performed by different surgeons with different levels of experience might favor the generalizability. As well, such studies can be benefited from split-mouth designs.

\section{Conclusion}

Within the limitations of this clinical trial, it seems that the use of 940-nm diode laser in gingivectomy surgery of canine-to-canine cosmetic smile lift might reduce postsurgical pain and bleeding compared to the traditional method of surgery using scalpels. Laser-assisted surgery might also reduce the need for suturing and patients' demand for analgesics.

\section{Competing interests}

The authors declare that they have no competing interests.

\section{Authors' contributions}

FS conceived and designed the study, selected the patients, performed the orthodontic treatments, interpreted the findings, and drafted the article. VR participated in the analyses, interpreted the findings, and drafted the article. NC designed the study, interpreted the findings, and drafted the article. MK conceived and designed the study, selected the patients, performed the gingivectomies, interpreted the findings, and drafted the article. All authors read and approved the final manuscript.

\section{Author details}

'Orthodontic Department, Dental Faculty, Mazandaran University of Medical Sciences, Sari, Iran. ${ }^{2}$ Iranian Tissue Bank and Research Center, Tehran University of Medical Sciences, Tehran, Iran. ${ }^{3}$ Department of Dental Anatomy and Morphology, Dental Branch, Islamic Azad University, Tehran, Iran. ${ }^{4}$ Laser Research Center of Dentistry, Dental Research Institute, Tehran University of Medical Sciences, Tehran, Iran. ${ }^{5}$ Department Of Periodontics, Dental Faculty, Mazandaran University of Medical Sciences, Sari, Iran.

\section{Published online: 09 December 2014}

\section{References}

1. Kau CH, Kantarci A, Shaughnessy T, Vachiramon A, Santiwong P, de la Fuente A, Skrenes D, Ma D, Brawn P. Photobiomodulation accelerates orthodontic alignment in the early phase of treatment. Prog Orthod. 2013; 14:30.

2. Mampieri G, Giancotti A. Invisalign technique in the treatment of adults with pre-restorative concerns. Prog Orthod. 2013; 14:40.

3. Sarver DM. Principles of cosmetic dentistry in orthodontics: Part 1. Shape and proportionality of anterior teeth. Am J Orthod Dentofacial Orthop. 2004; 126:749-53.

4. Khosravanifard B, Rakhshan V, Raeesi E. Factors influencing attractiveness of soft tissue profile. Oral Surg Oral Med Oral Pathol Oral Radiol. 2013; 115:29-37.

5. Rosa M, Olimpo A, Fastuca R, Caprioglio A. Perceptions of dental professionals and laypeople to altered dental esthetics in cases with congenitally missing maxillary lateral incisors. Prog Orthod. 2013; 14:34

6. Sarver DM, Yanosky M. Principles of cosmetic dentistry in orthodontics: Part 3. Laser treatments for tooth eruption and soft tissue problems. Am J Orthod Dentofacial Orthop. 2005; 127:262-64.

7. Sarver DM. Use of the $810 \mathrm{~nm}$ diode laser: soft tissue management and orthodontic applications of innovative technology. Pract Proced Aesthet Dent. 2006; 18:suppl 7-suppl 13.

8. Camargo PM, Melnick PR, Camargo LM. Clinical crown lengthening in the esthetic zone. J Calif Dent Assoc. 2007; 35:487-98.

9. Lombardo L, Ortan YO, Gorgun O, Panza C, Scuzzo G, Siciliani G. Changes in the oral environment after placement of lingual and labial orthodontic appliances. Prog Orthod. 2013; 14:28.

10. Rakhshan $\mathrm{H}$, Rakhshan $\mathrm{V}$. Effects of the initial stage of active fixed orthodontic treatment and sex on dental plaque accumulation: a preliminary prospective cohort study. Saudi Journal for Dental Research 2014; DOI: 10.1016/j.sjdr.2014.09.001 [ePub ahead of print].

11. Johal A, Katsaros C, Kiliaridis S, Leitao P, Rosa M, Sculean A, Weiland F, Zachrisson B. State of the science on controversial topics: orthodontic therapy and gingival recession (a report of the Angle Society of Europe 2013 meeting). Prog Orthod. 2013; 14:16.

12. Foley TF, Sandhu HS, Athanasopoulos C. Esthetic periodontal considerations in orthodontic treatment - the management of excessive gingival display. J Can Dent Assoc. 2003; 69:368-72.

13. Parker S. Low-level laser use in dentistry. Br Dent J. 2007; 202:131-38.

14. Seymour RA, Walton JG. Pain control after third molar surgery. Int J Oral Surg. 1984; 13:457-85. 
15. de Santana-Santos T, De Souza-Santos AA, Martins-Filho PR, da Silva LC, de Oliveira ESED, Gomes AC. Prediction of postoperative facial swelling, pain and trismus following third molar surgery based on preoperative variables. Med Oral Patol Oral Cir Bucal. 2013; 18:e65-70.

16. Slade GD, Foy SP, Shugars DA, Phillips C, White RP Jr. The impact of third molar symptoms, pain, and swelling on oral health-related quality of life. J Oral Maxillofac Surg. 2004; 62:1118-24.

17. Bienstock DA, Dodson TB, Perrott DH, Chuang SK. Prognostic factors affecting the duration of disability after third molar removal. J Oral Maxillofac Surg. 2011; 69:1272-77.

18. Capuzzi P, Montebugnoli L, Vaccaro MA. Extraction of impacted third molars. A longitudinal prospective study on factors that affect postoperative recovery. Oral Surg Oral Med Oral Pathol. 1994; 77:341-43.

19. Lago-Mendez L, Diniz-Freitas M, Senra-Rivera C, Gude-Sampedro F, Gandara Rey JM, Garcia-Garcia A. Relationships between surgical difficulty and postoperative pain in lower third molar extractions. J Oral Maxillofac Surg. 2007: 65:979-83.

20. Haraji A, Rakhshan V. Chlorhexidine gel and less difficult surgeries might reduce post-operative pain, controlling for dry socket, infection and analgesic consumption: a split-mouth controlled randomised clinical trial. J Oral Rehabil. 2014; DOI: 10.1111/joor.12230 [ePub ahead of print].

21. Nimeri G, Kau CH, Abou-Kheir NS, Corona R. Acceleration of tooth movement during orthodontic treatment - a frontier in orthodontics. Prog Orthod. 2013; 14:42

22. Ozcelik O, Cenk Haytac M, Kunin A, Seydaoglu G. Improved wound healing by low-level laser irradiation after gingivectomy operations: a controlled clinical pilot study. J Clin Periodontol. 2008; 35:250-54.

23. Newman MG, Takei HH, Klokkevold PR, Carranza FA. Carranza's clinical periodontology. 10th ed. Philadelphia: W.B. Saunders; 2006: p. 912-16.

24. Vescovi P, Corcione L, Meleti M, Merigo E, Fornaini C, Manfredi M, Bonanini M, Govoni P, Rocca JP, Nammour S. Nd:YAG laser versus traditional scalpel. A preliminary histological analysis of specimens from the human oral mucosa. Lasers Med Sci. 2010; 25:685-91.

25. Fornaini C, Rocca JP, Bertrand MF, Merigo E, Nammour S, Vescovi P. Nd:YAG and diode laser in the surgical management of soft tissues related to orthodontic treatment. Photomed Laser Surg. 2007; 25:381-92.

26. Matthews DC. Seeing the light - the truth about soft tissue lasers and nonsurgical periodontal therapy. J Can Dent Assoc. 2010; 76:a30.

27. Ize-lyamu IN, Saheeb BD, Edetanlen BE. Comparing the $810 \mathrm{~nm}$ diode laser with conventional surgery in orthodontic soft tissue procedures. Ghana Med J. 2013; 47:107-11.

28. Miyasaki M. Shedding light on the soft tissue laser. Signature. 2004; 11:11-3.

29. Pirnat S. Versatility of an $810 \mathrm{~nm}$ diode laser in dentistry: an overview. J Laser Health Acad. 2007; 4:1-9.

30. Yague-Garcia J, Espana-Tost AJ, Berini-Aytes L, Gay-Escoda C. Treatment of oral mucocele-scalpel versus CO2 laser. Med Oral Patol Oral Cir Bucal. 2009: 14:e469-74.

31. English JD, Peltomaki T, Pham-Litschel K. Soft-tissue diode laser surgery in orthodontics. St. Louis, Missouri: Mosby's orthodontic review: Elsevier Health Sciences; 2009: p. 272-76

32. Kravitz ND, Kusnoto B. Soft-tissue lasers in orthodontics: an overview. Am J Orthod Dentofacial Orthop. 2008; 133:S110-14.

33. Webert K, Cook RJ, Sigouin CS, Rebulla P, Heddle NM. The risk of bleeding in thrombocytopenic patients with acute myeloid leukemia. Haematologica. 2006: 91:1530-37.

34. Haraji A, Rakhshan V, Khamverdi N, Alishahi HK. Effects of intra-alveolar placement of $0.2 \%$ chlorhexidine bioadhesive gel on dry socket incidence and postsurgical pain: a double-blind split-mouth randomized controlled clinical trial. J Orofac Pain. 2013; 27:256-62.

35. Stubinger $S$, Saldamli B, Jurgens P, Ghazal G, Zeilhofer HF. Soft tissue surgery with the diode laser - theoretical and clinical aspects. Schweiz Monatsschr Zahnmed. 2006; 116:812-20.

36. D'Arcangelo C, Di Nardo Di Maio F, Prosperi GD, Conte E, Baldi M, Caputi S. A preliminary study of healing of diode laser versus scalpel incisions in rat oral tissue: a comparison of clinical, histological, and immunohistochemical results. Oral Surg Oral Med Oral Pathol Oral Radiol Endod. 2007; 103:764-73.

37. Kafas P, Stavrianos $C_{1}$ Jerjes $W$, Upile T, Vourvachis $M$, Theodoridis $M$ Theodoridis M, Stavrianou I. Upper-lip laser frenectomy without infiltrated anaesthesia in a paediatric patient: a case report. Cases J. 2009; 2:7138.
38. Erdinc AM, Dincer B. Perception of pain during orthodontic treatment with fixed appliances. Eur J Orthod. 2004; 26:79-85.

39. Xiaoting $L$, Yin T, Yangxi $C$. Interventions for pain during fixed orthodontic appliance therapy. A systematic review. Angle Orthod. 2010; 80:925-32

40. Bergius M, Kiliaridis S, Berggren U. Pain in orthodontics. A review and discussion of the literature. J Orofac Orthop. 2000; 61:125-37.

41. Krishnan V. Orthodontic pain: from causes to management - a review. Eur J Orthod. 2007; 29:170-79.

42. Krukemeyer AM, Arruda AO, Inglehart MR. Pain and orthodontic treatment. Angle Orthod. 2009; 79:1175-81.

43. Bergius $M$, Berggren $U$, Kiliaridis S. Experience of pain during an orthodontic procedure. Eur J Oral Sci. 2002; 110:92-8.

44. Rakhshan $\mathrm{H}$, Rakhshan V. Pain and discomfort perceived during initial stage of active fixed orthodontic treatment. Saudi Dental Journal. 2015

45. Scott P, Sherriff M, Dibiase AT, Cobourne MT. Perception of discomfort during initial orthodontic tooth alignment using a self-ligating or conventional bracket system: a randomized clinical trial. Eur J Orthod. 2008; 30:227-32.

46. Caso A, Hung L-K, Beirne OR. Prevention of alveolar osteitis with chlorhexidine: a meta-analytic review. Oral Surg Oral Med Oral Pathol Oral Radiol Endod. 2005; 99:155-59. 10.1016/j.tripleo.2004.05.009.

47. Grossi GB, Maiorana C, Garramone RA, Borgonovo A, Creminelli L, Santoro F. Assessing postoperative discomfort after third molar surgery: a prospective study. J Oral Maxillofac Surg. 2007; 65:901-17.

doi:10.1186/s40510-014-0066-5

Cite this article as: Sobouti et al:: Effects of laser-assisted cosmetic smile lift gingivectomy on postoperative bleeding and pain in fixed orthodontic patients: a controlled clinical trial. Progress in Orthodontics 2014 15:66

\section{Submit your manuscript to a SpringerOpen ${ }^{\circ}$ journal and benefit from:}

- Convenient online submission

- Rigorous peer review

- Immediate publication on acceptance

- Open access: articles freely available online

- High visibility within the field

- Retaining the copyright to your article

Submit your next manuscript at springeropen.com 